\title{
Políticas da identidade e da desidentificação
}

\author{
Arthur Bueno ${ }^{1}$
}

HONNETH, Axel; RANCIÈRE, Jacques. Recognition or Disagreement: A Critical Encounter on the Politics of Freedom, Equality, and Identity (ed. Katia Genel; Jean-Philippe Deranty)

São conhecidas as distâncias que separam duas linhas da teoria crítica contemporânea: de um lado, aquela desenvolvida explicitamente com essa denominação no âmbito do Instituto de Pesquisa Social de Frankfurt, cuja herança foi e continua sendo reivindicada por sucessivas gerações de teóricos; de outro, a tradição de pensamento consagrada nas décadas de 1960 e 1970, sobretudo na França, sob a alcunha de pós-estruturalismo, cuja genealogia é mais plural e menos ordenada do que a da linhagem frankfurtiana, mas cujas afinidades com esta última não deixaram de ser notadas em várias ocasiões. Embora qualquer caracterização geral das distâncias entre tais correntes seja necessariamente redutora, são notórias as suas diferentes posições a respeito de problemas como o estatuto da crítica, da normatividade, da política e da identidade. Desenvolvidas mais ou menos em paralelo, essas tradições intelectuais estabeleceram nas últimas décadas uma série de diálogos críticos entre seus principais representantes: aos debates de Jürgen Habermas com Michel Foucault e Jacques Derrida, bem como àqueles de Judith Butler com Seyla Benhabib

\footnotetext{
${ }^{1}$ Pós-doutorando e bolsista da Fundação Alexander von Humboldt e da Capes no Centro Max Weber de Estudos Culturais e Sociais Avançados da Universidade de Erfurt, onde atualmente leciona. Contato: arthur.bueno@unierfurt.de.
} 
|310 |

Políticas da identidade e...

e Nancy Fraser, entre outros, somam-se agora as discussões entre Axel Honneth e Jacques Rancière reunidas neste livro. Além de textos introdutórios dos organizadores, Katia Genel e Jean-Philippe Deranty, o volume contém dois capítulos nos quais cada filósofo comenta a obra do outro, seguidos da transcrição de um debate ocorrido em 2009 no Instituto de Pesquisa Social e, por fim, de artigos em que cada um deles apresenta as linhas gerais de seu método crítico.

O debate entre Axel Honneth e Jacques Rancière se organiza em torno de uma distinção fundamental compartilhada por ambos. Trata-se da contraposição entre a ordem política, com seus princípios normativos, suas formas de legitimação, seus sujeitos e suas identidades reconhecidas, de um lado, e os processos envolvidos tanto na emergência como na transformação dessa ordem e de suas distribuições de poder, de outro. É no modo de caracterizar tais momentos e suas relações, assim como no peso atribuído a cada um deles, que se encontram as principais divergências entre as filosofias políticas dos dois autores. É também a existência dessa distinção compartilhada que permite, por sua vez, a aproximação de suas perspectivas.

No centro do comentário crítico de Rancière está a sugestão de que as teses de Honneth sobre o reconhecimento se aproximam demasiadamente dos modos usuais pelos quais compreendemos esse termo. Seja no sentido cognitivo da coincidência de uma percepção atual com um conhecimento que já possuímos (mais destacado no francês réconnaissance), seja no sentido moral de uma resposta às demandas de outros sujeitos para serem tratados como pessoas autônomas (presente sobretudo no alemão Anerkennung), a noção de reconhecimento pressuporia uma concepção substantiva de identidade. Em um caso como no outro, tratar-seia de reconhecer algo que se apresenta à percepção cognitiva ou moral como uma entidade preexistente. $\mathrm{O}$ reconhecimento, nesse sentido, seria um ato de confirmação. Admitindo que a concepção articulada por Honneth não se reduz aos usos comuns dessa categoria, Rancière suspeita, contudo, que certas implicações do significado corrente do termo ainda se façam presentes em sua 
teoria do reconhecimento: esta exibiria, em suma, certa tendência a postular uma concepção identitária de sujeito - entendido como entidade prévia às relações de reconhecimento - e um modelo jurídico da comunidade - no qual tais relações são concebidas de modo dual, na forma da resposta de um sujeito à demanda de outro.

Contrapondo-se a essa perspectiva, Rancière se refere inicialmente a uma instância particular do reconhecimento, a esfera das relações amorosas, para apresentar uma concepção alternativa de sujeito e de comunidade. Apoiado em Proust, o filósofo francês argumenta que o amor não é simplesmente uma relação intersubjetiva. O que se tem, de início, não é um sujeito perante outro, mas sim "a aparição confusa de uma multiplicidade, um retalho impessoal em uma praia" (p. 88). Somente aos poucos, por meio de uma série de metamorfoses, essa multiplicidade confusa e impessoal vai assumir a forma personificada de uma entidade individual - "o rosto de uma pessoa, o objeto de amor, Albertine" (p. 88). Tanto o sujeito como o objeto de amor não preexistem à relação amorosa, mas se configuram na medida mesma em que ela se conforma: é a partir de um campo aberto de multiplicidades relativamente indeterminadas que pode ocorrer, mediante sucessivas alterações, "a construção de uma paisagem" (p. 89), de um universo no qual tais multiplicidades são incluídas e organizadas, assumindo a forma de uma relação entre amantes que se reconhecem um ao outro. Haveria, assim, um "momento artístico" inerente ao amor e a todas as relações de reconhecimento: trata-se daquele no qual é aberto um espaço de jogo marcado pela ausência de distinção clara entre "eu" e "tu", realidade e ficção, de modo que passa a ser possível construir-se a si mesmo e ao outro em seu interior.

Essa formação de subjetividades a partir de um solo não identitário, que excede a relação dual entre pessoas autônomas, é o que Rancière denomina "processo de subjetivação". Tem-se, com isso, uma modificação fundamental na categoria de sujeito: este não remete aqui à posse de uma identidade em um sistema de posições normativamente estabelecidas, mas é, pelo contrário, 
operador de uma desidentificação. Um sujeito, afirma Rancière, é "um processo de alteração" (p. 119). É antes de tudo pela ruptura com uma identidade dada num sistema de posições que ele se constitui: uma afirmação na primeira pessoa do plural como "nós, os trabalhadores" não designa uma identidade coletiva já existente, mas é um ato de enunciação operando uma ruptura com a ordem normativa estabelecida, na medida em que provoca uma abertura para aquele espaço de multiplicidades a partir do qual se pode constituir a si mesmo. Esse campo relativamente indeterminado e em devir é, segundo Rancière, o lugar do comum, do universal, de "qualquer um". O caráter desidentificatório dos processos de subjetivação implica, desse modo, a afirmação de uma igualdade radical: não se trata de meramente reivindicar o reconhecimento de uma competência possuída pelos membros de um grupo específico, mas de desempenhar a capacidade - que é de todos e de qualquer um - de participar dos assuntos comuns.

Esse processo de subjetivação se encerra, no entanto, no momento em que emerge um novo conjunto de normas, identidades e princípios de legitimação. Adentra-se, então, o domínio do que Rancière chama de "polícia". Definida como uma distribuição desigual de posições e competências que implica uma determinada "partilha do sensível", isto é, uma alocação das maneiras de ser, de fazer e de dizer que designa a cada corpo um lugar e uma tarefa específicos, essa ordem se enraíza naquele campo de multiplicidades impessoais que é o âmbito de qualquer um e, ao mesmo tempo, submete-o a um sistema hierárquico de identidades. A desigualdade se funda, portanto, na igualdade: ela constitui uma particularização do universal. Daí que, para Rancière, a atribuição de identidades apareça como aprisionadora: no romance de Proust, o momento em que Albertine surge como uma pessoa dotada de identidade é também aquele de sua captura pelo narrador - do qual ela, numa operação subjetivadora, acaba por escapar.

Disso resulta uma modificação importante da ideia de luta por reconhecimento: inscrita nesse terreno, ela deixa de consistir simplesmente num conjunto de demandas mútuas 
por parte de sujeitos já constituídos para ter suas identidades reconhecidas. Trata-se antes da configuração de um mundo comum, cuja emergência se dá, sobretudo, no momento em que as identidades prescritas por uma ordem normativa são postas em questão. Às lutas dos sujeitos pelo reconhecimento de suas identidades, Rancière opõe, assim, outra forma de reconhecimento: a reivindicação de não ser designado a uma identidade. Não se tem aí uma demanda para ser reconhecido como parte de um grupo obedecendo a normas específicas, mas antes a afirmação de que se possui os mesmos direitos, o mesmo respeito ou estima de qualquer um, isto é, de todos aos quais não é designada nenhuma identidade particular, nenhum lugar e competência específicos. Com essa reformulação, o filósofo francês pretende destacar que o reconhecimento de identidades é, com frequência, o lugar de uma profunda injustiça: afinal, há formas de desrespeito que se apoiam justamente em formas de respeito. O escravo na Grécia antiga era reconhecido em sua capacidade de fazer uso da linguagem e, no entanto, a identificação dessa competência constituía o reverso necessário da incompetência que lhe era atribuída; porque era reconhecido nesse aspecto específico, ele não o era em outros. $\mathrm{O}$ respeito concedido a uma identidade pode significar, no mesmo passo, a afirmação de uma incapacidade.

Seria errôneo, no entanto, atribuir a Honneth um conceito de reconhecimento meramente identitário, como aquele em geral referido pela noção de multiculturalismo. Embora admita, no debate com Rancière, certa tendência em seu pensamento a descrever as lutas por reconhecimento em termos que presumem a afirmação positiva de identidades dadas, interpretar sua obra desse modo significaria ignorar alguns de seus argumentos mais centrais. Com efeito, a identidade de que trata o filósofo alemão não se situa no passado ou no presente, mas no futuro. O ponto de partida metodológico de seu livro de 1992 são determinadas experiências de injustiça compreendidas, no interior da gramática normativa do reconhecimento, como negações ou restrições de dimensões basilares das relações intersubjetivas (amor, direito, solidariedade), às quais correspondem, por sua vez, formas de 
relações "distorcidas" ou "incompletas" dos indivíduos consigo mesmos (violação, exclusão, depreciação). São tais experiências, indicadas de início por emoções como vergonha e indignação, que fornecem o impulso para as lutas políticas: na medida em que sinalizam um mal-estar com as categorias de reconhecimento vigentes na ordem social, elas podem conduzir, em um momento seguinte, a conflitos por interpretações ou aplicações mais inclusivas e adequadas desses princípios. Não se trata, portanto, de conceber os conflitos sociais como maneiras de reassegurar identidades preexistentes. A integridade pessoal não constitui um dado a ser reafirmado, mas um telos imanente às lutas por reconhecimento, seu horizonte emancipatório - que Honneth, em escritos mais recentes, passou a caracterizar com o conceito institucional de liberdade social.

Além disso, a própria concepção honnethiana de reconhecimento inclui um componente desidentificatório, como já indica a importância do conceito winnicotiano de objeto transicional para sua compreensão da esfera amorosa, igualmente referido por Rancière na caracterização daquele momento artístico inerente ao amor. Tal componente não é, porém, exclusivo a essa esfera. Como Honneth agora afirma, as lutas por reconhecimento envolvem necessariamente um processo de desidentificação: na medida em que buscam reformular os princípios normativos vigentes, os agentes implicados no conflito social suspendem as categorias que os enquadravam até então. Por meio da luta, as identidades estabelecidas perdem seu caráter rígido e se abrem a novas interpretações. É significativo, entretanto, que esse momento seja caracterizado sobretudo como etapa transitória no caminho para novas normatividades e identidades. Embora aos processos de desidentificação seja atribuído um papel relevante no âmbito das lutas sociais, trata-se de um momento subordinado ao telos do reconhecimento como estabelecimento de ordens normativas mais abrangentes e inclusivas, às quais correspondem identidades pessoais progressivamente "completas" ou "intactas". Nestas últimas, como tais termos sugerem, não haveria lugar para a incompletude, para resíduos de não identidade, em suma: para 
aquele campo de multiplicidades indeterminadas que Rancière encara como o cerne inescapável da política. ${ }^{2}$

Não surpreende, assim, que os comentários de Honneth a respeito dos escritos de Rancière sigam em sentido inverso às objeções deste último. Criticando a rigidez excessiva da caracterização rancieriana da ordem política, o autor de Luta por reconhecimento sublinha que os princípios normativos vigentes estão abertos a novas interpretações e apropriações, podendo conduzir a compreensões mais inclusivas ou adequadas deles mesmos. Não faria sentido, portanto, reservar o conceito de intervenção política somente àquelas ocasiões excepcionais nas quais a ordem policial é questionada em sua totalidade. Propondo uma ampliação da categoria do político, Honneth sugere a existência de duas modalidades de luta por reconhecimento: "interna" e "externa" (p. 105). No primeiro caso, não se trata de colocar em questão a validade das gramáticas morais estabelecidas, mas de desenvolver novas interpretações e aplicações das normas em vigor. Tem-se aí, portanto, uma forma de política que não precisa ser entendida como descontínua em relação à ordem política vigente. O segundo caso, mais radical, consistiria naquele tipo de intervenção política tida em vista por Rancière: uma interrupção da ordem normativa com vistas não à aplicação mais adequada

\footnotetext{
2 Os comentários do filósofo francês se referem sobretudo aos argumentos de Honneth em Luta por reconhecimento, e o mesmo se fará nesta resenha. Em escritos mais recentes do autor, especialmente em $O$ direito da liberdade, publicado dois anos após o debate com Rancière, a categoria de identidade perdeu a centralidade que possuía no livro de 1992. A despeito disso, a concepção de liberdade social ali desenvolvida se sujeita a críticas semelhantes àquelas expostas nesta discussão: entendida como a institucionalização do reconhecimento mútuo na forma de papeis sociais complementares que fornecem, por sua vez, as condições para a formação de subjetividades autônomas, essa nova formulação do horizonte normativo da modernidade tampouco inclui explicitamente aquela multiplicidade indeterminada, desidentitária, como seu momento interno. Também neste caso, os aspectos não identitários tendem a ser encarados como insuficiências a serem superadas no caminho para um telos concebido em termos enfaticamente normativos.
} 
de um princípio já estabelecido, mas à superação da autoridade das normas estabelecidas - cujo exemplo típico seria a revolução burguesa, levada a cabo por uma "classe indefinida" (p. 105) que se subjetivou ao pôr em questão a ordem social como um todo. Com isso, Honneth tende a designar o que Rancière chama de processos de subjetivação como exclusivo ao segundo tipo de atividade política. As categorias de sujeito autônomo e de processo de subjetivação possuiriam esferas de aplicação bem delimitadas: respectivamente, as lutas internas e as lutas externas por reconhecimento. Curiosamente, essa é também a conclusão a que se pode chegar a partir dos argumentos de Rancière.

O filósofo francês rejeita, é verdade, a interpretação de seus escritos segundo a qual a atividade propriamente política envolveria somente atos insurrecionais externos ao sistema normativo, questionando-o em sua totalidade. Com efeito, na medida em que a ordem policial se erige a partir de um fundo de igualdade, a ação política não pode ser pensada como mera intervenção vinda de fora: a contestação da ordem vigente - da qual a "insurreição global" (p. 113) constitui apenas uma modalidade - se apoia, para Rancière, numa contradição interna entre o princípio político da indistinção igualitária e o princípio policial das competências desigualmente distribuídas.

Todavia, a caracterização da igualdade em termos puramente não normativos, como uma "evidência sensorial que precede qualquer juízo" (p. 118), conduz de fato a uma concepção da atividade política como suspensão das normatividades e identidades por meio da irrupção de algo que as precede e excede. No quadro da oposição entre desigualdade normativa e igualdade não normativa, a história tende a ser concebida como uma oscilação, infinita e não cumulativa, entre identidade aprisionadora e desidentificação liberadora, polícia e política. Repõe-se, ainda que no âmbito de um mesmo espaço político, a demarcação entre a interioridade interior da ordem policial e a exterioridade interior dos processos de subjetivação. É com basenessa delimitação que Rancière, de maneira similar a Honneth, opõe duas formas de luta, cada uma delas referida a um momento político 
específico: às demandas de um sujeito já constituído para ser reconhecido em sua identidade, realizadas no interior da ordem policial, se contraporiam aqueles conflitos nos quais se trata de reivindicar a não designação a uma identidade, o que caracterizaria o momento propriamente político da subjetivação. A consequência, em um filósofo como no outro, é a atribuição aos processos desidentitários de um caráter eminentemente disruptor, encerrando-se no momento em que é estabelecida uma nova ordem política, com seus sujeitos, normas e identidades.

O ponto em que os dois autores parecem concordar é, todavia, justamente onde se localiza um potencial que seus escritos não consideram de maneira sistemática. Com Honneth e contra Rancière, pode-se ressaltar o caráter internamente conflituoso e, por isso, eminentemente político das ordens normativas, para além de sua caracterização como mera "polícia". Com Rancière e contra Honneth, por sua vez, é possível considerar a multiplicidade própria aos momentos de subjetivação como aspecto crucial da política, para além de sua redução a mera etapa transitória no caminho para identidades intactas no interior de ordens do reconhecimento acabadas. Contudo, na medida em que ambos compreendem tais discordâncias da perspectiva de uma mesma delimitação entre o interior da ordem normativa policial e o exterior dos processos de interrupção subjetivadora, permanece inexplorada a possibilidade de considerar as efetivas imbricações - e não meramente as transições - entre essas duas instâncias da política.

Com efeito, em ambos os autores os momentos artísticooperativo e jurídico-normativo se mantêm em grande medida separados: nas fronteiras entre um e outro, tem-se a passagem da multiplicidade impessoal para as relações duais entre sujeitos autônomos, dos processos de desidentificação para identidades progressivamente integrais, da interrupção dos sistemas normativos para a ampliação dos princípios estabelecidos, da insurreição para as políticas reformistas. Parece não só possível como necessário, todavia, extrair as implicações cruzadas de suas objeções mútuas. Ao se insistir (com Honneth) no caráter aberto 
dos princípios normativos vigentes não se está, afinal, admitindo (com Rancière) a presença operativa, no "interior" da ordem policial, daquela multiplicidade característica dos processos de subjetivação? Assim também, evidenciar (com Rancière) o solo não identitário no qual se enraízam as lutas normativas por reconhecimento não é (com Honneth) reconhecer a atuação, nos momentos "externos" de interrupção subjetivadora, de princípios normativos e formas de identidade em vias de articulação?

Tal movimento nos distancia de qualquer separação estrita entre polícia e política, identidade e desidentificação, relação dual e multiplicidade impessoal, ordem normativa e processo de subjetivação, modelo jurídico e modelo artístico. Ele nos leva, pelo contrário, a reconhecer um momento desidentitário em toda forma de identidade e, inversamente, um momento identitário em todo processo de desidentificação - o mesmo valendo, mutatis mutandis, para a oposição homóloga entre antinormatividade e normatividade. Nessa perspectiva, o que aparece num dado momento como relações duais entre sujeitos dotados de autonomia, regidas por princípios normativos estabelecidos, não seria nada além de um estado mais consolidado daquelas multiplicidades que, como a própria ordem política, encontramse continuamente em devir. A identidade deixa de constituir necessariamente uma prisão, pois se encontra, em maior ou menor grau, atravessada por multiplicidades indeterminadas. Mas, pela mesma razão, tampouco uma noção de integridade pessoal completamente determinada, "intacta", pode figurar como telos emancipatório das lutas sociais.

Complica-se, desse modo, a contraposição entre uma noção (não teleológica) de igualdade compreendida em termos puramente não normativos, proposta por Rancière, e um conceito (teleológico) de liberdade concebido em chave estritamente normativa, defendido por Honneth. Complica-se, também, a oposição entre o aprisionamento das políticas identitárias e a transitoriedade das políticas desidentitárias. Se surge agora como problemática a compreensão restrita das lutas sociais pautada por noções substanciais de identidade, seja do presente 
(multiculturalismo) ou do futuro (autorrelação intacta), o mesmo se dá com sua rejeição em favor de figuras sublimadas de não identidade, seja do presente (interrupção subjetivadora) ou do futuro (por exemplo, certas interpretações da concepção marxiana do proletariado como classe destinada a eliminar a si mesma). Por isso, e pela série de questões correspondentes que suscita, a publicação do debate entre Honneth e Rancière vem em boa hora. 